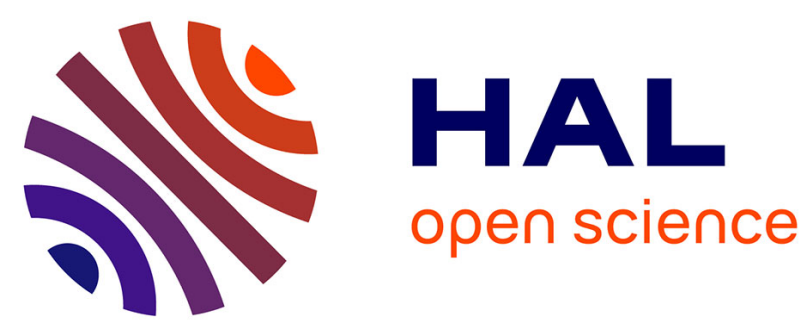

\title{
Genotypic variations among isolates of Marasmius quercophilus, a white-rot fungus isolated from evergreen oak litter
}

Anne Marie Farnet da Silva, M Roux, J. Le Petit

\section{- To cite this version:}

Anne Marie Farnet da Silva, M Roux, J. Le Petit. Genotypic variations among isolates of Marasmius quercophilus, a white-rot fungus isolated from evergreen oak litter. Canadian Journal of Botany, 1998, 77 (6), pp.884-890. 10.1139/b99-051 . hal-02071808

\section{HAL Id: hal-02071808 \\ https://hal.science/hal-02071808}

Submitted on 18 Mar 2019

HAL is a multi-disciplinary open access archive for the deposit and dissemination of scientific research documents, whether they are published or not. The documents may come from teaching and research institutions in France or abroad, or from public or private research centers.
L'archive ouverte pluridisciplinaire HAL, est destinée au dépôt et à la diffusion de documents scientifiques de niveau recherche, publiés ou non, émanant des établissements d'enseignement et de recherche français ou étrangers, des laboratoires publics ou privés. 


\title{
Genotypic variations among isolates of Marasmius quercophilus, a white-rot fungus isolated from evergreen oak litter
}

\author{
A.M. Farnet, M. Roux, and J . Le Petit
}

\begin{abstract}
Marasmius quercophilus is a white-rot basidiomycete isolated from evergreen oak litter. This fungus plays an extensive role in litter degradation because of its cellulase, pectinase, and laccase production. Our objective was to investigate the potential genotypic polymorphism of this species using RAPD (random amplified polymorphic DNA) and the amplification and the sequencing of fragments ITS (internal transcribed spacer) from the rRNA repeat. An intraspecies polymorphism was observed for the M. quercophilus isolates studied as suggested by the tree found with RAPD data: seven subgroups were defined. The minimum similarity coefficient observed in these groups was 0.278 . The sizes of fragments ITS 1 and ITS 2 were the same for each isolate (ITS 1: $320 \mathrm{bp}$ and ITS 2: $450 \mathrm{bp}$ ), and the percentages of nucleotide variation were 1.25 and $1.11 \%$, respectively. Few isolates from the studied population had the same RAPD pattern that would suggest a clonal development in some zones of the site of La Gardiole.
\end{abstract}

Key words: Marasmius quercophilus, intraspecific variability, ITS, RAPD.

Résumé : Marasmius quercophilus est un basidiomycète de la pourriture blanche isolé de la litière de chêne vert. Ce champignon joue un rôle important dans la dégradation de la litière de par sa production de cellulase, pectinase et laccase. Notre objectif consiste en la recherche d'un éventuel polymorphisme génotypique chez cette espèce en utilisant la RAPD (« random amplified polymorphic DNA ») et l'amplification suivie du séquençage des fragments ITS (« internal transcribed spacer ») à partir du cluster codant pour les ARNr. Un polymorphisme intraspécifique a été observé chez les isolats de $M$. quercophilus étudiés comme le suggère le dendrogramme trouvé à partir des données RAPD : sept sous-groupes ont été définis. Le coefficient de similarité minimum observé dans ces groupes était de 0,278. Les tailles des fragments ITS 1 et ITS 2 étaient identiques pour chaque isolat testé (ITS $1: 320 \mathrm{pb}$ et ITS $2: 450 \mathrm{pb}$ ) et le pourcentage de variation des nucleotides étaient de 1,25 et 1,11\%, respectivement. Quelques souches de la population étudiée présentaient le même profil RAPD ce qui suggère le développement de clones dans certaines zones du site de La Gardiole.

Mots clés : Marasmius quercophilus, variabilité intraspécifique, ITS, RAPD.

\section{Introduction}

Marasmius quercophilus is a white-rot fungus which colonizes evergreen oak litter, a typical Mediterranean ecosystem (Barbero and Loisel 1983). This fungus has not yet been the subject of investigations, although its enzymatic properties are of great interest. Tagger et al. (1998) have recently described the enzymatic properties of an isolate from the site of la Gardiole de Rians (Var, France), which is widely populated by evergreen oak, and thus the involvement of this fungus in litter degradation phenomena. Indeed, they have

A.M. Farnet, ${ }^{1}$ and J. Le Petit. Laboratoire de Microbiologie, Service 452, U.M.R. C.N.R.S. 6116, Institut Méditerranéen d'Ecologie et de Paléoécologie, Faculté des Sciences et Techniques de Saint Jérôme, 13397, Marseille, Cédex 20, France.

M. Roux. Laboratoire de Biomathématiques, Service 462, U.M.R. C.N.R.S. 6116, Institut Méditerranéen d'Ecologie et de Paléoécologie, Faculté des Sciences et Techniques de Saint Jérôme, 13397, Marseille, Cédex 20, France.

${ }^{1}$ Author to whom all correspondence should be addressed. e-mail: afarnet@hotmail.com showed the amylolytic, pectinolytic, and cellulolytic activities of this basidiomycete and also its extensive production of polyphenoloxidases such as laccases. Furthermore, the enzymatic systems involved in ligninolysis such as polyphenoloxidases have provoked considerable interest since they find applications in biotechnology (kraft pulp bleaching or aromatic pollutant degradation). In our study, 26 isolates were collected in the same site (La Gardiole de Rians). This site has been the subject of our research in many fields such as biological activity in the litter (Chabert et al. 1984), chemical analysis of tanins (Racon et al. 1987), and bacterial biodiversity (Périssol et al. 1993; Brunel et al. 1994).

The objective of this work was to study a potential genotypic polymorphism in $M$. quercophilus species since the genetics of this fungus has not yet been investigated. Genetic variations are mainly linked to mutations, genetic exchanges, spore spread, and adaptation to the environment. Thus, this study constituted a first attempt to investigate the biology and ecology of $M$. quercophilus, which seems to have an important role in the evergreen oak ecosystem. Furthermore, the genetic variability among the isolates studied may explain potential differences observed in their enzymatic properties. Molecular biology provides efficient tools such as RFLP (restriction fragment length polymorphism) after am- 
plification of the ITS (internal transcribed spacer) fragments from the rRNA repeat, or random amplified polymorphic DNA (RAPD) (Williams et al. 1990) to determine subspecies variability. The RAPD technique is not a timeconsuming and expensive method. This may explain the rapid growth of interest for this technology in behavioural ecology and population biology in the past few years. It is based on the use of random oligonucleotides with priming sites in an inverted orientation, which are close enough to permit PCR (polymerase chain reaction) amplification. Both of these methods have been applied successfully for the detection of polymorphisms and the classifi-cation for various fungal species (Demeke et al. 1992; Fegan et al. 1993; Kumeda and Asao 1996; Overmeyer et al. 1996). Here, we report on the successful use of RAPD in the analysis of genetic diversity of the $M$. quercophilus species.

\section{Materials and methods}

\section{Isolation of Marasmius quercophilus isolates}

Carpophores of $M$. quercophilus were collected at the site of La Gardiole de Rians (Var, France), in diverse areas and on different substrata: white or evergreen oak leaves, acorns, or wood (Table 1). In this site, the four areas (about $20 \mathrm{~m}^{2}$ ) were all $100 \mathrm{~m}$ distant. Dikaryotic isolates were obtained by using the rhizomorphic form of the fungus: cultures from fungal cap were obtained on a maltagar medium, $20 \mathrm{~g} \cdot \mathrm{L}^{-1}$ (Bio Mérieux, Marcy l'Etoile, France) containing $50 \mathrm{mg} \cdot \mathrm{L}^{-1}$ chloramphenicol (Sigma). Then, pure mycelial cultures were grown on a special agar medium (whole wheat flour, $20 \mathrm{~g} \cdot \mathrm{L}^{-1}$ ) that favours rhizomorph production. Rhizomorphs were cultured on a malt-agar medium $\left(20 \mathrm{~g} \cdot \mathrm{L}^{-1}\right)$.

\section{Enzymatic tests}

Cultures were grown on mineral medium (Kirk et al. 1978) and $0.5 \mathrm{~g} \cdot \mathrm{L}^{-1}$ cellulose. These cultures were homogenized with a sterile magnetic bar and were used to test for API Zym strips (Bio Mérieux, Marcy l'Etoile, France), which were incubated at $28^{\circ} \mathrm{C}$ for $24 \mathrm{~h}$. This technique is a semiquantitative micromethod designed for the research of enzymatic activities. It allows a rapid study of 19 various enzymatic reactions. Assays for aromatic compound transformation were realized in Monod tubes as described by Tagger et al. (1998). The aromatic compounds tested included $p$-coumaric acid, ferulic acid, and tannic acid (Sigma).

\section{DNA extraction}

Still cultures were grown in a $250-\mathrm{mL}$ Erlenmeyer flask containing $50 \mathrm{~mL}$ of malt extract $\left(20 \mathrm{~g} \cdot \mathrm{L}^{-1}\right)$ at $30^{\circ} \mathrm{C}$ for 15 days. Cultures were filtered on microglass filters (Whatman, F/D, $2.7 \mu \mathrm{m}$ ), and the mycelia were frozen in liquid nitrogen and ground to a fine powder in a mortar. An Eppendorf tube was filled with about $0.1 \mathrm{~g}$ of the powdered mycelium, $0.5 \mathrm{~mL}$ of extraction buffer $(0.5 \mathrm{M} \mathrm{NaCl}$, $10 \mathrm{mM}$ Tris-HCl, pH 7.5, $10 \mathrm{mM}$ EDTA, $1 \%$ SDS) was added, and the solution was well mixed and left to stand $10 \mathrm{~min}$. The same volume of phenol and $0.3 \mathrm{~mL}$ of chloroform - isoamyl alcohol $(2: 1, \mathrm{v} / \mathrm{v})$ were added. The mixture was shaken vigorously and left for $10 \mathrm{~min}$. The suspension was centrifuged at $10000 \times g$ for $15 \mathrm{~min}$, and the upper phase was removed carefully and transfered to a new Eppendorf tube. Ten microlitres of a $20 \%(\mathrm{w} / \mathrm{v})$ solution of RNase A (Sigma) was added and the mixture was incubated for $10 \mathrm{~min}$ at $37^{\circ} \mathrm{C}$. A volume of $0.4 \mathrm{~mL}$ of chloroform - isoamyl alcohol was added, and the solution was mixed and centrifuged at $10000 \times g$ for $10 \mathrm{~min}$. The upper phase was transferred to a fresh Eppendorf tube, and one volume of isopropanol was added. The suspension was mixed by inversion and put at $-20^{\circ} \mathrm{C}$ for $1 \mathrm{~h}$. After
Table 1. Origin of the 26 Marasmius quercophilus isolates from the site of la Gardiole de Rians (Var, France).

\begin{tabular}{|c|c|c|c|}
\hline Isolates & Natural substratum & Harvest date & Area \\
\hline $1 a$ & & Oct. 1990 & 3 \\
\hline $2 b$ & & Oct. 1990 & 3 \\
\hline $2 c$ & & Oct. 1990 & 3 \\
\hline $3 b$ & & June 1994 & 1 \\
\hline $4 b$ & & June 1994 & 2 \\
\hline $5 a$ & Wood & June 1994 & 1 \\
\hline $5 b$ & Wood & June 1994 & 1 \\
\hline 6 & & Sept. 1996 & 2 \\
\hline 8 & Wood & Sept. 1996 & 3 \\
\hline 9 & & Sept. 1996 & 1 \\
\hline 10 & Acorn & Sept. 1996 & 1 \\
\hline 13 & & Sept. 1996 & 2 \\
\hline 14 & & Sept. 1996 & 1 \\
\hline 15 & & Sept. 1996 & 4 \\
\hline 17 & & Sept. 1996 & 4 \\
\hline 18 & & Sept. 1996 & 2 \\
\hline 19 & Acorn & Sept. 1996 & 2 \\
\hline 21 & & Sept. 1996 & 3 \\
\hline 22 & & Sept. 1996 & 1 \\
\hline 23 & & Sept. 1996 & 1 \\
\hline 24 & & Sept. 1996 & 2 \\
\hline 25 & Acorn & Sept. 1996 & 3 \\
\hline 26 & & Sept. 1996 & 4 \\
\hline 27 & & Sept. 1996 & 3 \\
\hline 28 & White oak leaves & Sept. 1996 & 3 \\
\hline
\end{tabular}

Note: All the isolates were collected on evergreen oak leaves except for those specified. For isolate labelling, the number represented the carpophore, and the letter referred to the rhizomorph. When only one rhizomorph was isolated from the fungal cap culture, the isolate name included only a number.

centrifugation for $30 \mathrm{~min}$, the DNA pellet was washed with $70 \%$ ethanol and centrifuged briefly. The supernatant was removed, and the pellet was dried under vacuum $(10 \mathrm{~min})$. The pellet was resuspended in $20 \mu \mathrm{L}$ of TE buffer $(0.01 \mathrm{M}$ Tris- $\mathrm{HCl}, \mathrm{pH} 8.0,0.1 \mathrm{mM}$ EDTA)

\section{Amplification and sequencing of fragments ITS 1 and 2}

Primers M1, M2, M3, and M4 were described by White et al. (1990). Primers M1 (5'-TCCGTAGGTGAACCTGCGG-3') and M2 (5'-GCTGCGTTCTTCATCGATGC-3') were used for fragment ITS 1 amplification and primers M3 (5'-GCATCGATGAAGAACGCA GC-3') and M4 (5'-TCCTCCGCTTATTGATATGC-3') to amplify fragment ITS 2. The amplification conditions consisted of $75 \mathrm{mM}$ Tris- $\mathrm{HCl}$ (pH 9), $20 \mathrm{mM}\left(\mathrm{NH}_{4}\right)_{2} \mathrm{SO}_{4}, 0.01 \%$ Tween $20,2.5 \mathrm{mM}$ $\mathrm{MgCl}_{2}, 5 \mathrm{mM}$ of each dNTP (Eurogentec, Seraing, Belgium), $100 \mathrm{pmol}$ of each primer (synthesized by Eurogentec) using either primer M1 or M2, M3 or M4 with the appropriate primer, $5 \mathrm{ng}$ genomic DNA, and 1 unit of Taq Polymerase (Goldstar, Eurogentec) in a final reaction volume of $100 \mu \mathrm{L}$. The reaction mixtures were prepared on ice and sealed with a drop of mineral oil before thermal cycling. The amplification program was the same for the two primer pairs: 30 cycles consisting of $30 \mathrm{~s}$ denaturation $\left(93^{\circ} \mathrm{C}\right)$, $60 \mathrm{~s}$ primer annealing $\left(55^{\circ} \mathrm{C}\right)$, and $45 \mathrm{~s}$ extension $\left(72^{\circ} \mathrm{C}\right)$. This amplification was performed using the PTC 100 Thermal Controller (MJ Research, U.S.A.). The amplicons were separated on a $1.5 \%$ (w/v) agarose gel in TAE buffer with $0.1 \mu \mathrm{g} \cdot \mathrm{mL}^{-1}$ of ethidium bromide for $3 \mathrm{~h}$ at $4 \mathrm{~V} \cdot \mathrm{cm}^{-1}$. The size marker was a 100-bp ladder (GenSura Laboratories, Inc.) 
Fig. 1. The fragment ITS 1 and ITS 2 sequences of the four isolates specified: fragment ITS 1 (single strand) amplified with primer M1, fragment ITS 2 (single strand) amplified with primer M3. Different nucleotides are in boldface and underlined. The name of the isolate analysed is specified at the beginning of the sequence.

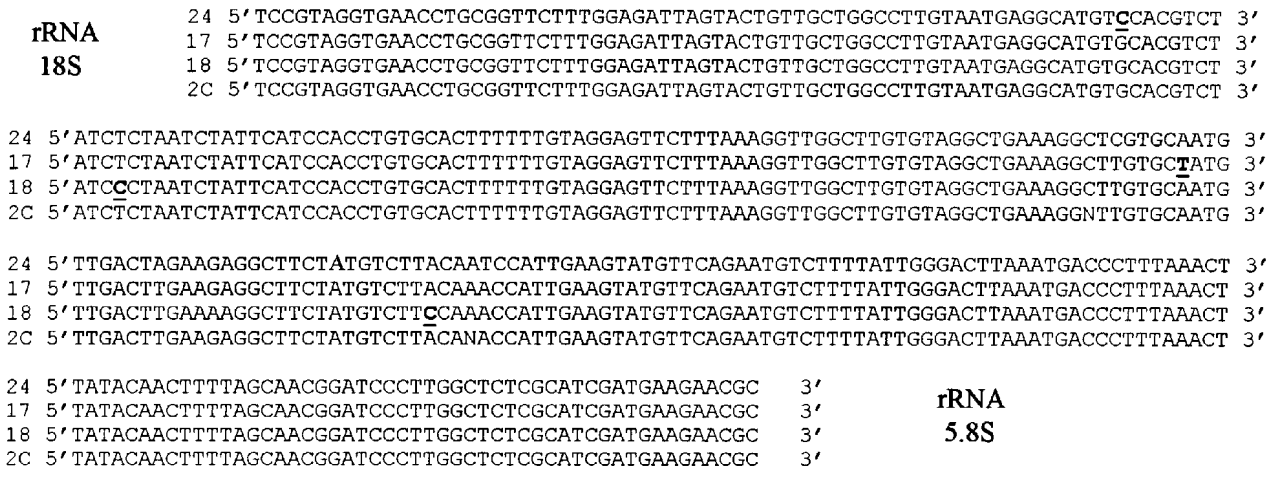

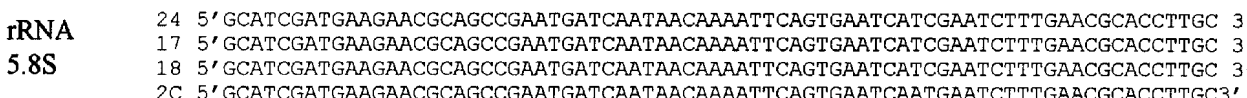

24 5'GCCCTCTGGTATTCCGGAGGGCATGCCTGTTTGAGTGTCATTAAATTCTCAACTTCAAAAGTTTTTGTTAACTTTTTGAAGCTT 3' 5'GCCCTCTGGTATTCCGGAGGGCATGCCTGTTTGAGTGTCATTAAATTCTCAACTTCAAAAGTTTTTGTTAACTTTTTGAAGCTT 3' 5'GCCCTCTGGTATTCCGGAGGGCATGCCTGTTTGAGTGTCATTAAATTCTCAACTTCAAAAGTTTTTGTTAACTTTTTGAAGCTT 3 , 5' GCCCTCTGGTATTCCGGAGGGCATGCCTGTTTGAGTGTCATTAAATTCTCAACTTCAAAAGTTTTTGTTAACTTTTTGAAGCTT $3^{\prime}$

4 5' GGATGTGGGGGTTTGCTAGCGTCTTTAGATGTTCGGCTCTCCTTAAAGTTATTAATGGGAATGTCTTTTGTTACACGATCCTGG 3' 5' GGATGTGGGGGTTCGCTAGCGTCTTTAGATGTTCGGCTCTCCTTAAAGTTATTAATGGGAATGTCTTTTGTTACACGAACCTGG $3{ }^{\prime}$ 5' GGATGTGGGGGTTTGCTAGCGTCTTTAGATG'TCGGCTCTCCTTAAAGTTATTAATGGGAATGTCTTTTGTTACACGATCCTGG $3^{\prime}$ 5' GGATGTGGGGGTTTGCTAGCGTCTTTAGATGTTCGCCTCTCCTTAAAGTTATTAATGGGAATGTCTTTTGTTACACGATCCTGG 3'

5'GTGTGATAATTATCTACACTTTGGATAGTCTAATGGTTCCATTGGGATTAATTGGTATTGCGATAAACTTTGCTTTACTTGAGT 3' 5'GTGTGATAATTATCTACACTTTTGATAGTCTAATGGTTCCATTGGGATTAATTGGTATTGCGATAAACTTTGCTTTAATTGAGT 3 5'GTGTGATAATTATCTACACTTT GGGATAGTCTAATGGTTCCATTGGGATTAATTGGTATTGCGATAAACTTTGCTTTACTTGAGT 3' 5'GTGTGATAATTATCTACACTTTCGATAGTCTAATGGTTCCATTGGGATTANTTGGTATTGCGATAAACTTTGCTTTACTTGAGT $3{ }^{\prime}$

24 5'CTCAGACGAAAAGATAAGTTCTGCTTTCTAACCGTCTGTGTTACATGGACAATTTATTGACTATTTGACCTCAAATCAGGTAGG $3{ }^{\prime}$ 17 5'CTCAGACGAAAAGATAAGTTCTGCTTTCTAACCGTCTGTGTTACATGGACAATTTATTGACTATTTGACCTCAAATCAGGTAGG 3' 8 5'CTCAGACGAAAAGATAAGTTCTGCTTTCTAACCGTCTGTGTTACATGGACAATTTATAGACTATTTGACCTCAAATCAGGTAGG 3' 2C 5' CTCAGACGAAAAGATAAGTTCTGCTTTCTAACCGTCTGTGTTACACGGACAATTTATT̄GACTATTTGACCTCAAATCAGGTAGG $3^{\prime}$

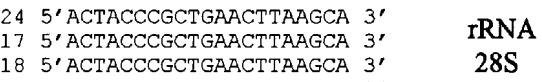

Each fragment was sequenced in both directions using the appropriate primer with the T7 DNA polymerase sequencing kit (Pharmacia).

\section{RAPD conditions}

The reaction concentrations were identical to those described above. Among 20 primers tested (Operon Technologies Inc., Alameda, Calif., U.S.A.) the primer OPA 09 was chosen since every isolate showed a response. The OPA 09 sequence is 5'GGGTAACGCC-3'. The reaction mixture was amplified through 30 cycles consisting of the following optimized program: $30 \mathrm{~s}$ denaturation $\left(94^{\circ} \mathrm{C}\right), 30 \mathrm{~s}$ primer annealing $\left(33^{\circ} \mathrm{C}\right)$, and $60 \mathrm{~s}$ extension $\left(72^{\circ} \mathrm{C}\right)$. We used the optional step "increment" of the PTC 100 thermocycler to realize a progressive increase in temperature $\left(0.5^{\circ} \mathrm{C} \cdot \mathrm{s}^{-1}\right)$ from annealing to extension. The amplified fragments were separated on a $1.5 \%$ agarose gel as described above. The band sizes were determined with the Image analysis software (Kodak Digital Science).

All amplification reactions were conducted at least three times in three separate experiments for each isolate.

\section{Statistical analysis}

Each of the RAPD bands was scored as discrete character in a binary matrix: 0 for absence and 1 for presence of reproducible bands. Genetic similarity was estimated from this binary matrix with the RAPDistance program version 1.04 (Armstrong et al. 1997) using Nei's genetic distance coefficient (Nei and Li 1979):

$$
\text { [1] } \quad D_{x y}=\frac{1-2 N_{x y}}{\left(N_{x}+N_{y}\right)}
$$

where $N_{x y}$ is the number of fragments shared by two isolates $x$ and $y$, and $N_{x}$ and $N_{y}$ are the number of fragments for isolate $x$ and $y$, respectively. Hierarchical cluster analysis was based on the neighbour-joining method (Saitou and Nei 1987).

\section{Results}

The use of primer pairs M1-M2 and M3-M4 led to the amplification of a single type of fragment in each case: about $320 \mathrm{bp}$ for the ITS 1 fragment and about $450 \mathrm{bp}$ for the ITS 2 fragment. Although the four M. quercophilus isolates sequenced did not show any differences in ITS 1 and ITS 2 sizes, the sequencing established nucleotide variability (Fig. 1): $1.25 \%$ for ITS 1 and $1.11 \%$ for ITS 2 (four nucleotides were different for fragment ITS 1 , five nucleotides for fragment ITS 2). 
Fig. 2. The tree of 26 Marasmius quercophilus isolates obtained from the RAPD results using the Nei and Li (1979) similarity coefficient and the neighbour-joining method (Saitou and Nei 1987). The tree was rooted using isolate $5 a$. The seven clusters observed are specified at the left of the tree.

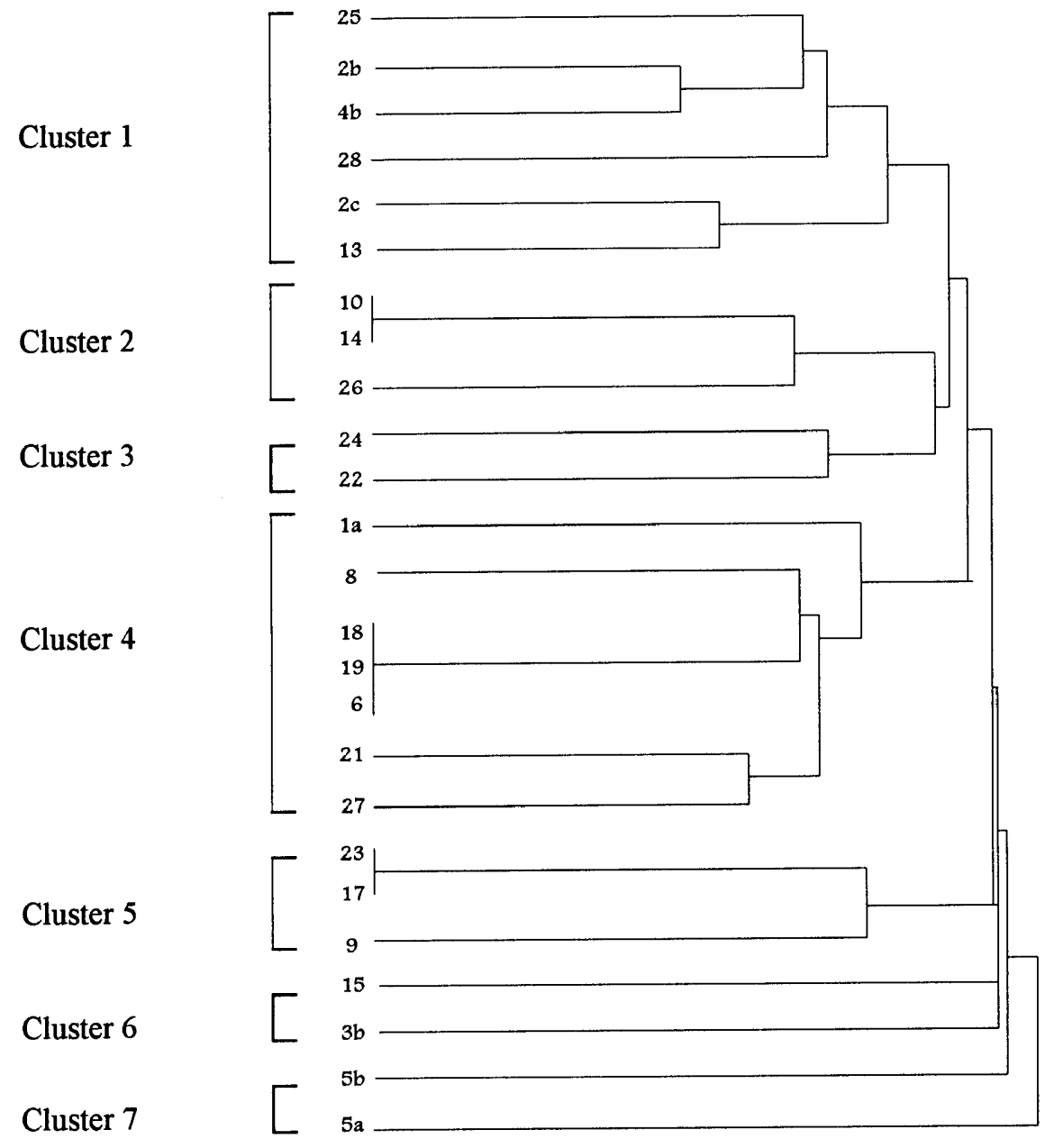

We tested the 20 primers of kit A provided by Operon Technologies, and we obtained a RAPD profile for the 26 isolates tested with oligonucleotide OPA 09 . With the other primers, a maximum of four isolates reacted to the amplification process. Each profile was reproducible from one amplification to another using newly extracted DNA from new cultures. The RAPD patterns obtained with primer OPA 09 showed 24 bands whose sizes varied from 80 to $6200 \mathrm{bp}$. Using statistical analysis by Nei and Li coefficient and the neighbour joining method as hierarchical clustering, we obtained a tree (Fig. 2). We observed that the branch lengths, which are proportional to genetic distance, were quite similar. This would suggest that the M. quercophilus isolates studied were fairly close genetically. Nevertheless, numerous deep branches in the tree demonstrated the presence of a polymorphism in this population. Indeed, the tree allowed us to group closely related isolates: cluster 1 , which included isolates $13,25,28,2 b, 2 c$, and $4 b$; cluster 2 with isolates 10 , 14 , and 26; cluster 3 with isolates 22 and 24; cluster 4 with isolates $1 a, 6,8,18,19,21$, and 27 ; cluster 5 with isolates 9 , 17 , and 23. Four other isolates were separated from the rest of the population, and they were grouped in two other clus- ters: cluster 6 with isolates 15 and $3 b$ and cluster 7 with isolates $5 a$ and $5 b$. The minimum similarity coefficient of Nei and $\mathrm{Li}$ (1979) observed in these different clusters was 0.278. The coefficient between isolates belonging to different clusters was greater, for example, the coefficient between isolates 10 and $1 a$ was equal to 0.856 (when two isolates are different, this coefficient is equal to 1 ). When two isolates are identical the coefficient of Nei and Li (1979) is equal to 0 : this was the case for some of the isolates studied, which were not differentiated (isolates 6, 18, and 19, and isolates 10 and 14). The tree also showed that isolates isolated from the same carpophore (carpophore 1, 2, 3, 4, or 5) were grouped in the same cluster. Some isolates collected from certain areas were grouped in the same clusters: clusters 1 and 4 in areas II and III and clusters 2, 5, 6, and 7 in areas I and IV.

Enzymatic tests such as acid phosphatase and $\beta$-galactosidase detection showed similar responses for all the isolates (data not shown). However, for other enzymes, we observed the same pattern in the different clusters described by the RAPD experiment. This was the case for the presence of ferulic acid (FA), tannic acid (TA), $p$-coumaric acid ( $p$-CA), 
Table 2. Ability to transform different substrates for the Marasmius quercophilus isolates in the different clusters determined by the RAPD study.

\begin{tabular}{|c|c|c|c|c|c|c|c|c|c|}
\hline Cluster & Isolate & $\mathrm{E}$ & $\mathrm{S}$ & FA & $p$-CA & TA & EL & NAG & Area \\
\hline & 25 & + & + & - & - & - & - & - & 3 \\
\hline & $2 b$ & + & + & - & - & - & - & - & 3 \\
\hline \multirow[t]{5}{*}{ Cluster 1} & $4 b$ & + & + & - & - & - & - & - & 2 \\
\hline & 28 & + & + & - & - & - & - & - & 3 \\
\hline & $2 c$ & + & + & - & - & - & - & - & 3 \\
\hline & 13 & + & + & - & - & - & - & - & 2 \\
\hline & 10 & - & - & - & - & + & - & + & 1 \\
\hline \multirow[t]{2}{*}{ Cluster 2} & 14 & - & - & - & - & + & - & + & 1 \\
\hline & 26 & - & - & - & - & + & - & + & 4 \\
\hline \multirow[t]{5}{*}{ Cluster 3} & 24 & - & - & - & + & - & - & + & 2 \\
\hline & 22 & - & - & - & + & - & - & + & 1 \\
\hline & $1 a$ & - & - & - & - & - & + & - & 3 \\
\hline & 8 & - & - & - & - & - & + & - & 3 \\
\hline & 18 & - & - & - & - & - & + & - & 2 \\
\hline \multirow[t]{4}{*}{ Cluster 4} & 19 & - & - & - & - & - & + & - & 2 \\
\hline & 6 & - & - & - & - & - & + & - & 2 \\
\hline & 21 & - & - & - & - & - & + & - & 3 \\
\hline & 27 & - & - & - & - & - & - & + & 3 \\
\hline \multirow[t]{3}{*}{ Cluster 5} & 23 & - & - & - & - & - & - & + & 1 \\
\hline & 17 & - & - & - & - & - & - & + & 4 \\
\hline & 9 & - & - & - & - & - & - & + & 1 \\
\hline \multirow[t]{2}{*}{ Cluster 6} & 15 & - & + & + & - & - & - & - & 4 \\
\hline & $3 b$ & - & + & + & - & - & - & - & 1 \\
\hline \multirow[t]{2}{*}{ Cluster 7} & $5 b$ & - & + & - & - & - & + & - & 1 \\
\hline & $5 a$ & - & + & - & - & - & + & - & 1 \\
\hline
\end{tabular}

Note: Enzymatic tests were esculin (E), salicillin (S), ferulic acid (FA), $p$-coumaric acid ( $p$-CA), and tannic acid (TA) transformation and esterase-lipase (EL) and $N$-acetyl $\beta$-glucosaminidase (NAG) presence.

esculin (E), and salicillin (S) transformation, esterase-lipase (EL), and $N$-acetyl $\beta$-glucosaminidase (NAG) (Table 2).

\section{Discussion}

ITS analysis did not distinguish between isolates; all the isolates were quite similar, and the sequences of fragments ITS 1 and 2 showed few differences for the four isolates tested (1.25 and $1.11 \%$, respectively). Although both the ITS region and the intergenic spacer of the nuclear rRNA repeat unit evolve quickly and thus are useful in describing intraspecific genetic variations (White et al. 1990), intraspecies homology has already been reported using analysis of ITS fragments. For example, in the case of both Fusarium oxysporum Schlechtendahl isolates (Edel et al. 1996) and Aspergillus (Kumeda and Asao 1996) section Flavi (A. flavus Eries, A. parasiticus Speare, A. oryzae Ahlburg, A. sojae Sakagushi \& Yamada, A. tamarii Kita), no differences were detected in the restriction patterns of fragments ITS 1 and 2 although isolates were collected from several different countries in both cases. Furthermore, Zimand et al. (1994) have observed great homology among Trichoderma harzianum Rifai isolates which were isolated from various sites (United States, Norway, Germany, Sweden). Extensive genetic stability has also been found in the plant pathogenic fungus Calonectria morganii Crous, Alfenas \& Wingfield
(Overmeyer et al. 1996) and among Metarhizium anisopliae Metschnikoff isolates (Bidochka et al. 1994).

In this study, the RAPD data showed an overall genetic stability, since the branch lengths of the tree, which are proportional to genetic distance, were quite similar. This can be explained by the intraspecific nature of the study. Extensive genetic exchanges within a population lead to a decrease in genetic diversity, since this genetic flow occurs easily between isolates of the same species. But we also observed a greater degree of homology between some isolates forming subgroups, which demonstrated polymorphism in the population studied (the minimum coefficient of similarity was 0.278 ). This extensive polymorphism may be due to different environmental pressures, which vary with the area where the fungi were collected. Furthermore, a progressive separation of fungal hyphae even in a quite limited site may lead to genetic divergence. These interpretations are consistent with the fact that the isolates (except cluster 3) grouped in the same cluster were collected in the same areas (II and III; I and IV). These observations suggest that the environmental influences (temperature, moisture, $\mathrm{pH}$ ) are the same in areas I and IV and in areas II and III. Thus, the isolates grouped in clusters 1 and 4 and clusters 2, 5, 6, and 7 seem to have adapted to the same environmental factors in areas II and III and in areas I and IV, respectively. However, this hypothesis has to be considered with caution, since the environmental factors of the different areas are not yet clearly defined, and 
some of the isolates collected on various substrata (acorn, evergreen oak or white oak leaves) were grouped in the same cluster. Assigbetse et al. (1994) have also attributed the differentiation of Fusarium oxysporum f.sp. vasinfectum to the geographical location of the isolates. De la Bastide et al. (1994) have successfully distinguished Laccaria bicolor Maire isolates depending on the area where the isolates were collected. Rohel et al. (1997) have shown that some Erynia neoaphidis Remaudière \& Hennebert isolates from different continents showed extensive homology, while other isolates of the same species presented differences even when they were collected in the same area in France. This demonstrated the wide variety of results possible.

The heterogeneity of this population was illustrated by the enzymatic data: isolates belonging to the same cluster had certain similar phenotypic properties. Phenotypic potential alone can not be used to estimate the variability of a population, but it can reflect heterogeneity previously detected by genome analyses. Wildman (1995) has also shown that the geographic location and the substrate of origin of Fusarium acuminatum Ellis \& Everhart isolates influenced the morphological aspects of this fungus. Furthermore, toxin production was affected by the habitat of the different isolates of this fungal species. The Fusarium compactum Wollenweber isolates, which were also analysed in this study, differed in their carbon utilization patterns depending on the sites where they were collected.

In our RAPD study, several isolates from the same carpophore were grouped. It was expected that these isolates would be genetically close, since their genetic difference was due to meiosis alone, these dikaryons having been obtained from the recombination of the monokaryons produced by the same polysporic culture. The grouping of these isolates has thus showed the ability of the RAPD method to analyse genotype relationships at different taxonomic levels. The isolates that were considered as identical $(6,18$, and 19; 10 and 14) were collected at the same time (1996). Isolates 6,18 , and 19 were collected in the same area (area II) and isolates 10 and 14 were collected in area I. The hypothesis of a clone dispersed in a site has already been described (Turner et al. 1997). Cooke and Rayner (1984) have also reported clone spread in ecosystems in the case of different basidiomycete populations. The somatic incompatibility loci are numerous and multiallelic. Both these situations minimize the chance of two isolates in a population having exactly the same somatic incompatibility alleles. This limits genetic exchanges and encourages the development of clonal populations.

This first attempt to analyse the $M$. quercophilus genome showed genetic polymorphism in this species. Further studies will help us to better describe this species, for example, using isolates from other sites or other geological substrata (such as siliceous soils). At the same time, this would allow us to investigate the potential influence of environmental factors on a fungal population.

\section{References}

Armstrong, J., Gibbs, A., Peakall, R., and, Weiller, G. 1997. RAPDistance programs, version 1.04 edition. Computer pro- gram distributed by the authors. Research School of Biological Sciences, Institute of Advanced Studies, Canberra, Australia.

Assigbetse, K.B., Fernandez, D., Dubois, M.P., and Geiger, J.P. 1994. Differentiation of Fusarium oxysporum f. sp. races on cotton by random amplified polymorphic DNA (RAPD) analysis. Phytopathology, 84: 622-626.

Barbero, M., and Loisel, R. 1983. Les chênaies vertes du sud-est de la France mediterranéenne: valeurs phytosociologiques, dynamiques et potentielles. Phytocoenologia, 11: 225-244.

Bidochka, M.J., McDonald, M.A, St. Leger, R.J., and Roberts, D.W. 1994. Differentiation of species and isolates of entomopathogenic fungi by random amplification of polymorphic DNA (RAPD). Curr. Genet. 25: 107-113.

Brunel, B., Périssol, C., Fernandez, M., Boeufgras, J.M., and Le Petit, J. 1994. Occurrence of Bacillus species on evergreen oak leaves. FEMS Microbiol. Ecol. 4: 331-342.

Chabert A., Le Petit, J., Loisel, R., Matheron, R., and Tagger, S. 1984. Dégradation biologique de la litière de chêne vert dans deux forêts de la région provençale (Var, France), Ecol. Mediterr. 1-2: 171-181.

Cooke, R.C., and Rayner, A.D.M. 1984. Ecology of saprotrophic fungi. Longman, London, U.K.

De la Bastide, P.Y., Kropp, B.R., and Piché, Y. 1994. Spatial distribution and temporal persistence of discrete genotypes of the ectomycorrhizal fungus Laccaria bicolor (Maire) Orton. New Phytol. 127: 547-556.

Demeke, T., Adams, R.P., and Chibbar, R. 1992. Potential taxonomic use random amplified polymorphic DNA (RAPD): a case study in Brassica. Theor. Appl. Genet. 84 : 990-994.

Edel, V., Steinberg, C., Gautheron, N., and Alabouvette, C. 1996. Evaluation of restriction analysis of polymerase chain reaction (PCR)-amplified ribosomal DNA for the identification of $\mathrm{Fu}$ sarium species. Mycol. Res. 101: 179-187.

Fegan, M., Manners, J.M., Maclean, D.J., Irwin, J.A.G., Samuels, K.D.Z., Holdom, D.G., and Li, D.P. 1993. Random amplified polymorphic DNA markers reveal a high degree of genetic diversity in the entomopathogenic fungus Metarhizium anisopliae var. anisopliae, J. Gen. Microbiol. 139: 2075-2081.

Kirk, T.K., Schultz, E., Connors, W.J., Lorenz, L.F., and Zeikus J. 1978. Influence of culture parameters on lignin metabolism by Phanerochaete chrysosporium. Arch. Microbiol. 11: 277-285.

Kumeda, Y., and Asao, T. 1996. Single-strand conformation polymorphism analysis of PCR-amplified ribosomal DNA internal transcribed spacers to differentiate species of Aspergillus section Flavi. Appl. Environ. Microbiol. 62: 2947-2952.

Nei, M., and Li, W.H. 1979. Mathematical model for studying genetic variation in terms of restriction endonucleases. Proc. Natl. Acad. Sci. U.S.A. 76: 5269-5273.

Overmeyer, C., Lünneman, S., Von Wallbrunn, C., and Meinhardt, F. 1996. Genetic variability among isolates and sexual offspring of the plant pathogenic fungus Calonectria morganii on the basis of random amplification of polymorphic DNA (RAPD) and restriction fragment length polymorphism (RFLP). Curr. Microbiol. 33: 249-255.

Périssol, C., Roux, M., and Le Petit, J. 1993. Succession of bacteria attached to evergreen oak leaf surfaces. Eur. J. Soil Biol. 29: 167-176.

Racon, L., Sadaka, N., Gil, G., Le Petit, J., Matheron, R., PoinsotBalaguer, N., Sigoillot, J.C., and Woltz, P. 1987. Histological and chemical changes in tannic compounds of evergreen oak leaf litter. Can. J. Bot. 66: 663-667.

Rohel, E., Couteaudier, Y., Papierok, B., Cavelier, N., and Dedryver, C.A. 1997. Ribosomal internal transcribed spacer size 
variation correlated with RAPD-PCR pattern polymorphisms in the entomopathogenic fungus Erynia neoaphidis and some closely related species. Mycol. Res. 101: 573-579.

Saitou, N., and Nei, M. 1987. The neighbour-joining method: a new method for reconstructing phylogenetic trees. Mol. Biol. Ecol. 4: 406-425.

Tagger, S., Périssol, C., Gil, G., Vogt, G., and Le Petit J. 1998. Phenoloxidases of the white-rot fungus Marasmius quercophilus isolated from an evergreen oak litter (Quercus ilex, L.). Enzyme Microb. Technol. 23: 372-379.

Turner, D., Kovacs, W., Lieckfeld, E., Peter, B., Arisan-Atac, I., Strauss, J., Samuels, G.J., Borner, T., and Kubicek, C.P. 1997. Biogeography and phenotypic variation in Trichoderma sect.
Longibrachiatum and associated Hypocrea species. Mycol. Res. 4: 449-459.

White, T.J., Bruns, T., Lee, S., and Taylor, J. 1990. PCR protocols: a guide to methods and applications. Academic Press, Inc.

Wildman, H.G. 1995. Influence of habitat on the physiological and metabolic diversity of fungi. Can. J. Bot. 73: 907-916.

Williams, J.G.K., Kubelik, A.R., Livak, K.J., Rafalski, J.A., and Tingey, S.V. 1990. DNA polymorphisms amplified by arbitrary primers are useful as genetics markers. Nucleic Acids Res. 18: 6531-6535.

Zimand, G., Valinsky, L., Elad, Y., Chet, I., and Manulis, S. 1994. Use of the RAPD procedure for the identification of Trichoderma isolates. Mycol. Res. 98: 531-534. 